\title{
BMJ Open Hypertension in the South African public healthcare system: a cost-of- illness and burden of disease study
}

\author{
Ciaran N Kohli-Lynch (D , , ${ }^{1,2}$ Agnes Erzse, ${ }^{1}$ B Rayner, ${ }^{3}$ Karen J Hofman ${ }^{1}$
}

\begin{abstract}
To cite: Kohli-Lynch CN, Erzse A, Rayner B, et al. Hypertension in the South African public healthcare system: a costof-illness and burden of disease study. BMJ Open 2022;12:e055621. doi:10.1136/ bmjopen-2021-055621
\end{abstract}

- Prepublication history and additional supplemental material for this paper are available online. To view these files, please visit the journal online (http://dx.doi.org/10.1136/ bmjopen-2021-055621)

Received 03 August 2021 Accepted 07 January 2022

Check for updates

(c) Author(s) (or their employer(s)) 2022. Re-use permitted under CC BY-NC. No commercial re-use. See rights and permissions. Published by BMJ.

${ }^{1}$ SAMRC/Wits Centre for Health Economics and Decision Science, PRICELESS, University of the Witwatersrand, Faculty of Health Sciences, Johannesburg, Gauteng, South Africa

${ }^{2}$ Center for Health Services \& Outcomes Research, Feinberg School of Medicine, Northwestern University,

Chicago, Illinois, USA

${ }^{3}$ Division of Nephrology and Hypertension, Department of Medicine, University of Cape Town, Cape Town, Western Cape, South Africa

Correspondence to Dr Ciaran N Kohli-Lynch; ciaran.kohli-lynch@ northwestern.edu

\section{ABSTRACT}

Objectives To quantify the health and economic burden of hypertension in the South African public healthcare system.

Setting All inpatient, outpatient and rehabilitative care received in the national public healthcare system.

Participants Adults, aged $\geq 20$ years, who receive care in the public healthcare system.

Outcomes Worksheet-based models synthesised data from multiple sources to estimate the burden of disease, direct healthcare costs, and societal costs associated with hypertension. Results were disaggregated by sex. Results Approximately 8.22 million $(30.8 \%, 95 \% \mathrm{Cl}$ $29.5 \%$ to $32.1 \%$ ) South African adults with no private health insurance have hypertension. Hypertension was estimated to cause 14000 (95\% Cl 11100 to 17200$)$ ischaemic heart disease events, 13300 (95\% Cl 10600 to 16300$)$ strokes and 6100 (95\% Cl 4970 to 7460$)$ cases of chronic kidney disease annually. Rates of hypertension, hypertension-related stroke and hypertension-related chronic kidney disease were greater for women compared with men.

The direct healthcare costs associated with hypertension were estimated to be ZAR 10.1 billion $(95 \% \mathrm{Cl} 8.98$ to 11.3 billion) or US\$0.711 billion ( $95 \% \mathrm{Cl} 0.633$ to 0.793 billion). Societal costs were estimated to be ZAR 29.4 billion ( $95 \% \mathrm{Cl} 26.0$ to 33.2 billion) or US $\$ 2.08$ billion (95\% Cl 1.83 to 2.34 billion). Direct healthcare costs were greater for women (ZAR 6.11 billion or US\$0.431 billion) compared with men (ZAR 3.97 billion or US\$0.280 billion). Conversely, societal costs were lower for women (ZAR 10.5 billion or US $\$ 0.743$ billion) compared with men (ZAR 18.9 billion or US\$1.33 billion).

Conclusion Hypertension exerts a heavy health and economic burden on South Africa. Establishing costeffective best practice guidelines for hypertension treatment requires further research. Such research will be essential if South Africa is to make progress in its efforts to implement universal healthcare.

\section{BACKGROUND}

High blood pressure (BP), or hypertension, caused an estimated 10.7 million deaths worldwide in 2015 and rates were higher in low-income and middle-income countries. ${ }^{1}$ South Africa is an upper middle-income country in which hypertension is a highly prevalent condition. $^{2-5}$ Hypertension was

\section{Strengths and limitations of this study}

This is the first study of the economic burden of hypertension in South Africa.

- A bottom-up approach was used for estimating direct costs.

- A human capital approach with disability-adjusted life year indexing was used to calculate societal costs.

- Despite data limitations, model inputs regarding the prevalence of hypertension, healthcare utilisation and the price of healthcare resources were all derived from South African data.

- Our estimate of societal costs may underestimate activity in the 'informal' labour market and informal work (eg, housekeeping, caretaking).

responsible for around 47000 deaths in South Africa in 2000. Since then, its prevalence has grown from $25 \%$ to greater than $40 \% .^{2}$

While the proportion of the South African population with uncontrolled hypertension has stabilized in recent years, ${ }^{4}$ rates of diagnosis, treatment and control remain low. $^{36}$ These rates are lower for low-income individuals, those with fewer years of education and those who receive care in the public healthcare system. $^{2} 7$ Funding prevention, public screening and treatment campaigns may improve population health and reduce health disparities.

Around $85 \%$ of the South African population has no private health insurance, ${ }^{8}$ yet private healthcare accounts for more than half of the country's health-related expenditure. ${ }^{9}$ The government is in the process of creating a National Health Insurance (NHI) programme to address inequalities in access to comprehensive healthcare. ${ }^{10}$ The NHI programme will produce a centralised financing source for public healthcare, which aims to improve the quality of public healthcare and increase its allotted budget.

There are considerable knowledge gaps related to the health and economic cost of hypertension and cardiovascular disease 
(CVD) in low-income and middle-income countries. ${ }^{11}$ No previous studies have considered the economic burden of hypertension in South Africa. Calculating the cost of hypertension and the prevalence of its complications will help decision-makers target public healthcare resources more efficiently, improving the sustainability of the NHI programme.

The first objective of this study was to estimate the incidence and prevalence of hypertension and hypertensionrelated complications among individuals who receive care in the South African public healthcare system. The second objective was to calculate the annual healthcare and societal costs associated with hypertension in these individuals.

\section{METHODS}

This study followed the Consolidated Health Economic Evaluation Reporting Standards reporting recommendations (online supplemental eTable 1).

\section{Study parameters}

We adopted a public healthcare sector perspective. The population of interest was adults aged $\geq 20$ years receiving healthcare in the public health sector. We estimated prevalence of hypertension, number of hypertension-related complications and costs associated with hypertension in this population. Costs were disaggregated into two categories: direct healthcare and societal costs. A time horizon of 1 year was adopted. No discount rate was applied.

\section{Approach}

Two worksheet-based costing models were developed in Microsoft Excel to synthesise data from multiple sources. One model was produced for men and another for women, due to previously observed sex differences in the age distribution of these populations, rates of hypertension and hypertension-related complications and employment rates. ${ }^{2} 1213$

The costing models accept a range of epidemiologic and cost inputs, which are described below, and output rates of hypertension-related complications, direct healthcare costs and societal costs associated with hypertension. CIs were derived for hypertension-related complications and costs through probabilistic analysis. We probabilistically sampled epidemiologic model input parameters and produced 1000 estimates of hypertension-related health and cost outcomes. We reported mean and $95 \%$ CIs for all model outputs.

After communication with the National Department of Health, non-governmental research institutions and examination of the open data portal for health services research, ${ }^{14}$ it was established that no national data set exists, which details public healthcare expenditure disaggregated by disease type. It was determined that a bottom-up costing approach with secondary data sources was necessary. Analysis was disaggregated by sex and age-group (young adults-aged 20-39 years, middle adults—aged 40-69 years and older adults—aged $\geq 70$ years).

\section{Population size and public healthcare utilisation}

Population size was informed by Statistics South Africa (SSA) mid-year estimates, disaggregated by sex. ${ }^{15}$ Careseeking behaviour was informed by recent national surveys. The proportion of screening and other outpatient care that occurs in the public healthcare system (70.7\%) was derived from the Demographic and Health Survey $2016 .{ }^{16}$ The proportion of acute care that occurs in the public healthcare system $(71.5 \%)$ and the proportion of the population who have no private health insurance $(83.6 \%)$ were derived from the General Household Survey $2018 .^{8}$ In both cases, the 'public healthcare system' referred to healthcare provided in government hospitals, government clinics, community health centres and other public sector facilities.

\section{Hypertension rates}

Hypertension prevalence, diagnosis, treatment and control were estimated in the National Income Dynamics Survey (NIDS) 2017, a large-scale national survey of population health, which is publicly available. ${ }^{17}$ Analysis was conducted in the subset of respondents without private health insurance. All NIDS 2017 analyses were completed in the $R$ programming language (V.4.0.4, $\mathrm{R}$ Core Team). Participants were asked about hypertension diagnosis, medications and CVD risk factors. ${ }^{18}$ In addition, respondents had systolic blood pressure (SBP) and diastolic blood pressure (DBP) measured two times. We used the average of these values in our analysis. Individuals without SBP readings were omitted from the analysis. Cross-sectional sample weights were used to ensure that results were representative of the contemporary South African population. ${ }^{19}$ Further information on NIDS 2017 and the way participants' blood pressure was recorded is contained in the online supplemental material.

Hypertension was split into five categories, in accordance with the National Department of Health's Adult Primary Care (APC) Guidelines 2019-2020. ${ }^{20}$ These were normotension (SBP $<140 \mathrm{~mm} \mathrm{Hg}$ and DBP $<90 \mathrm{~mm} \mathrm{Hg}$ ), grade 1 a (SBP 140-159 mm Hg or DBP 90-99, with no other cardiovascular risk factors), grade 1b (SBP 140-159 $\mathrm{mm} \mathrm{Hg}$ or DBP 90-99, with another cardiovascular risk factor), grade 2 (SBP 160-179 mm Hg or DBP 100-109 $\mathrm{mm} \mathrm{Hg}$ ) and grade 3-or 'severe' hypertension (SBP $\geq 180$ or DBP $\geq 110 \mathrm{~mm} \mathrm{Hg}$ ). If an individual had differential grades of systolic and diastolic BP, they were assigned the more severe of the two categories. For example, an individual with SBP $150 \mathrm{~mm} \mathrm{Hg}$ (grade 1) and DBP $105 \mathrm{~mm}$ $\mathrm{Hg}$ (grade 2) would be assigned grade 2 hypertension. 'Other cardiovascular risk factors' considered in the APC guidelines were smoking, diabetes, age $\geq 55$ years for men, age $\geq 65$ years for women, waist circumference $\geq 94 \mathrm{~cm}$ for men and waist circumference $\geq 80 \mathrm{~cm}$ for women.

Prevalence of SBP categories was estimated in two subsets of the population: all individuals and individuals 
not currently receiving antihypertensive medication. Overall prevalence was calculated as the sum of hypertensive individuals not currently receiving antihypertensive medication plus the number receiving antihypertensive medication. Hypertension prevalence, diagnosis, treatment and control rates were estimated for the overall population and separately for men and women. CIs for these rates were computed using incomplete beta functions with sample size based on the estimated variance of the proportion. ${ }^{21}$

\section{Screening costs}

Costing for facility use and healthcare worker time came from the Uniform Patient Fee Schedule (UPFS) 2020. ${ }^{22}$ The UPFS is a set of tariffs for public health services, including both health practitioner and facility fees. The tariffs are updated annually and apply to all patients using public services. ${ }^{23}$ There are three types of facilities in the public healthcare system, which generally increase in price: district, regional, and tertiary.

There is limited guidance regarding screening in the APC 2019-2020 or the South African Hypertension Society (SAHS) practice guidelines. ${ }^{24}$ It was assumed that all screenings would be undertaken by a nurse practitioner in a district-level health facility. The cost of a screening visit was estimated to be ZAR 144 (US\$10) (table 1, online supplemental eTable 2).

\section{Management costs}

To estimate the cost of hypertension management, recommended resource use in the APC 2019-2020 guideline was itemised. Resource use included medication, testing and check-up visit costs (table 1, online supplemental eTable 2). The proportion of the population that reported antihypertensive medication use in NIDS 2017 received ongoing treatment. We assumed a proportion of the population with untreated hypertension that would commence treatment over the course of a year. Specifically, we assumed that new treatment would commence according to the overall treatment rate of individuals with hypertension in the wider population.

The treatment steps contained in the APC guidelines are described in the online supplemental material. Initial treatment intensity depended on untreated BP and treatment intensified with failure to control $\mathrm{BP}$ on lower treatment steps. A decision tree was constructed to predict the number of patients receiving each treatment step (online supplemental eFigure 1). The tree predicted the number of steps required to control hypertension in different subgroups of patients. Probability of successful BP control during treatment was estimated in NIDS 2017. We were not able to estimate clinician compliance to APC guidelines. We assumed that all treated patients received guideline-compliant care, and expert opinion was elicited to validate this assumption.

Unit costs for antihypertensive medications were derived from National Treasury contracts. ${ }^{25}$ Outpatient visit costs came from the UPFS 2020. It was assumed that
Table 1 Cost input derivation of costs outlined in text and online supplemental eTables 3-10

\begin{tabular}{|c|c|c|}
\hline Parameter & $\begin{array}{l}\text { Cost (ZAR } \\
\text { 2020) }\end{array}$ & Sources \\
\hline \multicolumn{3}{|l|}{ Visit costs } \\
\hline Screening visit & 144.00 & 22 \\
\hline Check-up visit & 229.00 & 22 \\
\hline \multicolumn{3}{|l|}{ Medication, cost per day } \\
\hline Hydrochlorothiazide 12.5 mg & 0.14 & 25 \\
\hline Hydrochlorothiazide $25 \mathrm{mg}$ & 0.12 & 25 \\
\hline Enalapril 10 mg & 0.16 & 25 \\
\hline Enalapril $20 \mathrm{mg}$ & 0.23 & 25 \\
\hline Amlodipine $5 \mathrm{mg}$ & 0.12 & 25 \\
\hline Amlodipine $10 \mathrm{mg}$ & 0.16 & 25 \\
\hline Spironolactone $25 \mathrm{mg}$ & 0.46 & 25 \\
\hline \multicolumn{3}{|l|}{ Hypertensive crises } \\
\hline Urgencies & 2499.66 & 2225 \\
\hline Emergencies & 17571.66 & 2225 \\
\hline \multicolumn{3}{|l|}{ Hypertension-related complications } \\
\hline Acute ischaemic heart disease & 16407.20 & 22253969 \\
\hline Chronic ischaemic heart disease & 1554.21 & 22253969 \\
\hline Acute stroke & 23883.23 & 22253969 \\
\hline Chronic stroke & 1235.21 & 22253969 \\
\hline $\begin{array}{l}\text { Haemodialysis for end-stage } \\
\text { renal disease }\end{array}$ & 301694.92 & 22253969 \\
\hline $\begin{array}{l}\text { Peritoneal dialysis for end-stage } \\
\text { renal disease }\end{array}$ & 86227.42 & 22253969 \\
\hline $\begin{array}{l}\text { Transplant for end-stage renal } \\
\text { disease }\end{array}$ & 138523.75 & 43 \\
\hline \multicolumn{3}{|l|}{ Societal costs } \\
\hline Disability-adjusted life year, men & 119669.00 & $45-4751$ \\
\hline $\begin{array}{l}\text { Disability-adjusted life year, } \\
\text { women }\end{array}$ & 91755.82 & $45-4751$ \\
\hline Physician visit (1.5 hours), men & 20.48 & $1345-4751$ \\
\hline Physician visit (1.5 hours), women & 15.70 & $1345-4751$ \\
\hline Hypertensive crisis (2 days), men & 655.27 & $132045-4751$ \\
\hline $\begin{array}{l}\text { Hypertensive crisis ( } 2 \text { days), } \\
\text { women }\end{array}$ & 502.43 & $132045-4751$ \\
\hline
\end{tabular}

all check-ups would be administered by physicians in district-level facilities. The overall cost for a check-up visit was ZAR 229 (US\$16).

\section{Hypertensive crises}

Most patients with severe hypertension are asymptomatic. ${ }^{24}$ Some will experience hypertensive crises and require acute medical care. Hypertensive crises can be classified as urgencies or emergencies. The latter are more severe and involve ongoing organ damage. Published studies were used to estimate the proportion of patients with severe hypertension that experience a hypertensive crisis $(5.5 \%)$ and the proportion of crises that are emergencies $(32 \%){ }^{27-29}$ Optimal treatment for hypertensive 
crises is outlined in the SAHS 2014 guidelines. ${ }^{24}$ These guidelines were itemised and costed (table 1, online supplemental eTable 3), producing costs of around ZAR 2500 (US\$176) for urgencies and ZAR 17600 (US\$1239) for emergencies.

\section{Complications-event rates}

We estimated the proportion of complications attributable to hypertension along with their acute and chronic costs. Five types of complication were considered: ischaemic heart disease (IHD), stroke, chronic kidney disease (CKD), heart failure (HF) and hypertensive heart disease (HHD). While this is not an exhaustive list of conditions affected by hypertension, they were the complications most commonly included in previous costing studies, and there is strong evidence that hypertension is causative in their incidence. ${ }^{30}{ }^{31}$ We estimated the populationattributable fraction (PAF) for each of these conditions associated with hypertension.

Overall rates of conditions which may be caused by hypertension were derived from the Global Burden of Disease Survey (GBDS) 2019, which combined multiple national surveys of demographics and health to produce sex-disaggregated estimates of incidence, prevalence and disability-adjusted life years (DALYs) for different illnesses in South Africa. ${ }^{32}$ This is a publicly available data set. ${ }^{33}$ DALYs are a metric which combine both the years of life lost from a health-related condition alongside the years of healthy life lost due to disability. ${ }^{34}$ We took agespecific data from the GBDS and adjusted them with SSA population data (online supplemental eTable 4). Due to perceived issues with HF coding, GBDS researchers decided to distribute its morbidity and mortality among multiple conditions. The majority of HF events are redistributed to IHD, stroke and HHD. ${ }^{35}$

The GBDS provides direct estimates for the proportion of CKD events caused by hypertension. The PAF of IHD, stroke and HHD associated with hypertension were estimated separately. ${ }^{36}$ The PAF quantifies the proportion of events attributable to a given risk factor. It is estimated by predicting how many events would have occurred in subgroups of a population if a risk factor had been eliminated and comparing that number to actuality. We estimated the number of complications that would be prevented if mean SBP values in hypertensive subgroups were lowered to the mean value for normotensives. HRs of 1.24 and 1.16 per $10 \mathrm{~mm} \mathrm{Hg}$ increase in SBP were employed for IHD and stroke, respectively. ${ }^{37}$ For HHD, the HR decreased with older age and ranged from 1.63 to 2.86 per $10 \mathrm{~mm} \mathrm{Hg}$ increase in SBP. ${ }^{38}$

For the probabilistic analysis, we sampled hypertension rates from a Dirichlet distribution based on the NIDS 2017 analysis outlined above and IHD, stroke, CKD and HHD rates from Gamma distributions of the GBDS 2019 data.

\section{Complications-costs}

To estimate the cost of IHD, stroke and CKD, published literature was reviewed to produce itemised lists of the costs associated with acute and chronic events. For acute events, we itemised costs for one hospitalisation and subsequent rehabilitative services (ie, physiotherapy and occupation therapy for stroke and transplant patients). For chronic events, we itemised costs for 1 year of treatment. Unit costs were assigned to these items from publicly available data.

A cost-effectiveness analysis ${ }^{39}$ from South Africa combined clinical guidelines with expert opinion to create 'impact inventories', which list the different types of resource use associated with chronic conditions, including IHD, stroke and renal disease. These inventories included resource use for acute and chronic care and informed resource use in our model (table 1 , online supplemental eTables 5 and 6 ). Unit costs were estimated with contemporary data, which included the UPFS 2020, the Government Employee Medical Scheme 2019 tariffs and public contracts for pharmaceutical products. ${ }^{22} 25{ }^{40}$ Estimated costs for IHD and stroke hospitalisations were around ZAR 16400 (US\$1160) and ZAR 23900 (US\$1680), respectively. Corresponding annual chronic care costs were ZAR 1550 (US\$110) and ZAR 1240 (US\$87).

In its early stages, CKD is largely treated through management of other CVD risk factors. ${ }^{41}$ A proportion of patients with hypertension-related CKD will develop end-stage renal disease (ESRD). The South African Renal Registry provided information on the prevalence of ESRD and the proportion of patients with CKD receiving haemodialysis, peritoneal dialysis and kidney transplantation in the public healthcare system (online supplemental eTable 7). ${ }^{42}$ Itemised lists of resource use for dialysis and kidney transplant patients were taken from the cost-effectiveness paper described above (table 1, online supplemental eTable 8) ${ }^{39}$ Resource use for kidney transplantation was derived from a cost-of-illness study of type 2 diabetes in South Africa. ${ }^{43}$ Estimated annual costs for haemodialysis and peritoneal dialysis were ZAR 302 000 (US\$21 300) and ZAR 86200 (US\$6080), respectively. The cost of kidney transplantation was estimated to be around ZAR 139000 (US\$9770).

\section{Societal costs}

A human capital approach was employed to calculate the societal cost of hypertension. This approach assumes that all healthy time losts due to illness (ie, years of life lost and years of health life lost due to disability) lead to lost productivity. ${ }^{44}$ Every DALY experienced by an individual aged $20-65$ years attributable to hypertension was assigned the value of one gross domestic product (GDP) per worker, weighted by the proportion of the overall population who are currently employed (the "employment-topopulation ratio'). ${ }^{45}$ Societal costs were only included for the population without private health insurance. The GDP per worker for South Africa was estimated to be ZAR 276000 (US\$19 500). ${ }^{464}$ The employment-to-population ratio was $43.3 \%$ for men and $33.2 \%$ for women. ${ }^{13}$ 


\section{Sensitivity analysis}

The effect of key modelling parameters on cost estimates was examined with one-way sensitivity analysis. Epidemiologic model inputs were systematically altered between upper and lower bounds derived from the NIDS 2017 analysis and other secondary data analysis. The resulting change in direct, societal and overall costs were recorded. Results from the sensitivity analysis were presented in a tornado diagram.

\section{General cost assumptions}

The price of healthcare goods and services may vary across time and setting. ${ }^{48}$ Costs indexed in years prior to 2020 were inflated using SSA's regularly updated consumer price index estimates for medical services and medical products. ${ }^{49}$ In addition, costs derived from private healthcare sources were deflated using the ratio of prices paid in private versus public healthcare settings. ${ }^{43}$ All costs were converted to US dollars to provide international context for results. ${ }^{47}$

\section{Patient and public involvement}

Patients and the general public were not directly involved in this study.

\section{RESULTS}

\section{Burden of disease}

We estimated that around 8.22 million $(30.8 \%$, 95\% CI $29.5 \%$ to $32.1 \%$ ) adults aged $\geq 20$ years without private health insurance have hypertension (table 2). This proportion increased to $53.1 \%$ (95\% CI $50.7 \%$ to $55.7 \%$ ) for adults aged $\geq 40$ years. Rates of hypertension were greater for women and increased with age (table 3, online supplemental eTable 9). Around 51.1\% (95\% CI 49.2\% to $52.9 \%$ ) of hypertension was diagnosed, $93.2 \%$ (95\% CI $91.6 \%$ to $94.5 \%$ ) of diagnosed hypertension was treated and $54.7 \%$ (95\% CI $52.2 \%$ to $57.3 \%$ ) of treated hypertension was controlled (online supplemental eTable 10). Diagnosis of existent hypertension, likelihood of receiving treatment and likelihood of $\mathrm{BP}$ control on treatment were substantially higher for women and increased with age.

Hypertension leads to a significant burden of disease, which increases with age. It was responsible for around $17.9 \%$ (95\% CI $15.4 \%$ to $20.5 \%$ ) of IHD incidence, $27.6 \%$ (95\% CI $24.2 \%$ to $31.2 \%)$ of stroke incidence and $82.8 \%$ of HHD incidence (95\% CI $79.5 \%$ to $85.6 \%$ ) (online supplemental eTable 11). Hypertension causes around 31100 (95\% CI 29000 to 369000 ) hypertensive crises, 14000 (95\% CI 11100 to 17 200) IHD events, 13300 (95\% CI 10600 to 16 300) strokes and 6110 (95\% CI 4970 to 7460) cases of CKD annually (table 2, online supplemental eTable 12). Many individuals suffer from chronic health conditions caused by hypertension, leading to around 517000 DALYs. Women were estimated to experience more hypertensive crises, hypertension-related strokes, hypertension-related cases of CKD and $50.6 \%$ of
Table 2 Hypertension-related complications treated in South African public healthcare system

\begin{tabular}{|c|c|}
\hline $\begin{array}{l}\text { Hypertension-related } \\
\text { condition }\end{array}$ & $\begin{array}{l}\text { Counts of conditions per year } \\
(95 \% \mathrm{Cl})\end{array}$ \\
\hline \multicolumn{2}{|c|}{ Total number with hypertension* (\% of age-group, $95 \% \mathrm{Cl}$ ) } \\
\hline Ages $\geq 20$ years & $8219164(30.8,29.5$ to 32.1$)$ \\
\hline Ages $\geq 40$ years & $6428960(53.1,50.7$ to 55.7$)$ \\
\hline \multicolumn{2}{|l|}{ Hypertensive crises } \\
\hline Hypertensive urgencies & 10033 (8401 to 11897$)$ \\
\hline Hypertensive emergency & 21068 (17 640 to 24983$)$ \\
\hline \multicolumn{2}{|l|}{ Ischaemic heart disease } \\
\hline $\begin{array}{l}\text { Ischaemic heart disease, } \\
\text { incidence }\end{array}$ & 13991 (11 082 to 17193$)$ \\
\hline $\begin{array}{l}\text { Ischaemic heart disease, } \\
\text { prevalence }\end{array}$ & $125974(103829$ to 150104$)$ \\
\hline $\begin{array}{l}\text { Ischaemic heart disease, } \\
\text { DALYs }\end{array}$ & 99927 (83 936 to 118119$)$ \\
\hline \multicolumn{2}{|l|}{ Stroke } \\
\hline Stroke, incidence & 13308 (10 611 to 16336$)$ \\
\hline Stroke, prevalence & 113056 (95 427 to 132961$)$ \\
\hline Stroke, DALYs & $156813(132327$ to 182448$)$ \\
\hline \multicolumn{2}{|l|}{ Chronic kidney disease } \\
\hline $\begin{array}{l}\text { Chronic kidney disease, } \\
\text { incidence }\end{array}$ & 6105 (4974 to 7459$)$ \\
\hline $\begin{array}{l}\text { Chronic kidney disease, } \\
\text { prevalence }\end{array}$ & 119814 (108219 to 131274$)$ \\
\hline $\begin{array}{l}\text { Chronic kidney disease, } \\
\text { DALYs }\end{array}$ & 88913 (71937 to 107987$)$ \\
\hline \multicolumn{2}{|l|}{ Hypertensive heart disease } \\
\hline $\begin{array}{l}\text { Hypertensive heart disease, } \\
\text { DALYs }\end{array}$ & 171202 (144 414 to 198969$)$ \\
\hline
\end{tabular}

*HTN grades 1-3 or currently receiving antihypertensive medication.

DALY, disability-adjusted life year.

total hypertension-related DALYs (online supplemental eTable 13).

\section{Cost of hypertension}

The total cost of hypertension was ZAR 39.5 billion (95\% CI 35.0 to 44.5 billion) or US $\$ 2.79$ billion (95\% CI 2.47 to 3.31 billion). Total direct healthcare costs associated with hypertension were estimated to be ZAR 10.1 billion (95\% CI 8.98 to 11.3 billion) or US $\$ 0.711$ billion (95\% CI 0.633 to 0.793 billion) (table 4 , online supplemental eTable 14). Direct hypertension screening and management costs were accounted for ZAR 8.75 billion (95\% CI 7.66 to 9.88 billion) or US $\$ 0.617$ billion (95\% CI 0.541 to 0.697 billion). Stroke was responsible for the largest amount of hypertension-related complication costs, followed by IHD and hypertensive crises. The societal cost of hypertension was estimated to be ZAR 29.4 billion (95\% CI 26.0 to 33.2 billion) or US $\$ 2.08$ billion (95\% CI 1.83 to 2.34 
Table 3 Prevalence of SBP categories in South African adults without private health insurance

\begin{tabular}{|c|c|c|c|c|c|}
\hline \multirow[b]{2}{*}{ Population } & \multicolumn{5}{|c|}{ Hypertension category } \\
\hline & Normotensive & Grade 1a & Grade 1b & Grade 2 & Grade 3 \\
\hline \multicolumn{6}{|l|}{ Proportion of population (95\% Cl) } \\
\hline Young adults (age 20-39 years) & 87.1 (86.1 to 88.0$)$ & $5.0(4.4$ to 5.6$)$ & 4.9 (4.3 to 5.5$)$ & $2.2(1.8$ to 2.6$)$ & $0.9(0.7$ to 1.2$)$ \\
\hline Middle adults (age 40-69 years) & 67.1 (65.5 to 68.6$)$ & 3.8 (3.1 to 4.6$)$ & $\begin{array}{l}16.5 \text { (15.3 to } \\
17.7)\end{array}$ & 8.4 (7.5 to 9.3$)$ & 4.2 (3.6 to 4.9$)$ \\
\hline \multicolumn{6}{|c|}{ SBP (mm Hg) within category, mean (95\% Cl) } \\
\hline Overall population & 114 (91 to 137) & 136 (117 to 156$)$ & 132 (114 to 152$)$ & 144 (123 to 172$)$ & 162 (140 to 197$)$ \\
\hline Young adults (age $20-39$ years) & 112 (90 to 135$)$ & 137 (117 to 156$)$ & 133 (112 to 153$)$ & 147 (120 to 159$)$ & 165 (140 to 191$)$ \\
\hline
\end{tabular}

Normotension: SBP $<140 \mathrm{~mm} \mathrm{Hg}$ and DBP $<90 \mathrm{~mm} \mathrm{Hg}$, grade 1a: SBP 140-159 mm Hg or DBP 90-99 mm Hg with no other CVRFs, grade 1b: SBP 140-159 mm Hg or DBP 90-99 mm Hg with another CVRF, grade 2: SBP 160-179 mm Hg or DBP 100-109 mm Hg, grade 3: SBP $\geq 180 \mathrm{~mm} \mathrm{Hg}$. If an individual had differential grades of systolic and diastolic BP, they were assigned the more severe of the two categories. Additional cardiovascular risk factors: smoking, diabetes, men aged $\geq 55$ years, women aged $\geq 65$ years, men waist circumference $\geq 94 \mathrm{~cm}$, women waist circumference $\geq 80 \mathrm{~cm}$.

CVRF, cardiovascular risk factor; DBP, diastolic blood pressure; SBP, systolic blood pressure.

billion). This was approximately $74.4 \%$ of the total cost of hypertension.

Direct healthcare costs of hypertension were higher for women (ZAR 6.11 billion or US $\$ 0.431$ billion) compared with men (ZAR 3.97 billion or US $\$ 0.280$ billion) (online supplemental eTable 14). Conversely, societal costs of hypertension were lower for women (ZAR 10.5 billion or US $\$ 0.743$ billion) compared with men (ZAR 18.9 billion or US $\$ 1.33$ billion).

Sensitivity analysis showed that the proportion of the population with private health insurance, the societal cost of a DALY, the proportion of care that takes place in the public versus the private healthcare sector and the overall prevalence of hypertension had the largest impact on total cost estimates (figure 1). Substantial reductions in direct healthcare and societal costs could be achieved if the prevalence of hypertension was to be reduced.

\section{DISCUSSION}

To our knowledge, this is the first study of the economic burden of hypertension in South Africa and it shows that hypertension exerts a heavy economic burden. Our estimate of hypertension's direct healthcare cost represents $4.4 \%$ of the combined projection for national and provincial public health expenditure in $2020 .^{50}$ The total cost of ZAR 39.5 billion or US $\$ 2.79$ billion represents around $0.76 \%$ of South Africa's GDP. ${ }^{51}$ The management of hypertension must be considered in the context of other healthcare spending priorities. Previous studies have assessed the annual healthcare cost of type 2 diabetes in the public healthcare sector (US $\$ 0.160$ billion) ${ }^{43}$ the annual cost of smoking (US $\$ 2.54$ billion) ${ }^{52}$ and the annual cost associated with alcohol abuse (US\$2.27 billion).$^{53}$

We estimated that around $30.8 \%$ of adults aged $\geq 20$ years without private health insurance have hypertension. This is lower than previous studies, but it is based on more contemporaneous data. ${ }^{2-45455}$ We also estimated that hypertension leads to 517000 DALYs annually. This is substantially more than a previous burden of disease study, which analysed data from $2000 .{ }^{12}$

While the majority of South Africans receive care in the public healthcare system, around $15 \%$ have private health insurance. We did not quantify the health and economic costs associated with hypertension in privately insured individuals. Previous studies have shown that income is not a significant predictor of elevated BP in South Africa, but it is a major determinant of hypertension awareness, treatment and control. ${ }^{45}$ Higher income individuals, including those with private health insurance, are more likely to receive treatment and are more likely to be employed. The average cost of hypertension management and the societal cost of hypertension-related complications may be greater in this population. Conversely, rates of hypertension-related complications are likely lower in this population due to better BP control.

We estimated that expenditure on hypertension management represents a large proportion of the direct healthcare costs associated with the condition. It is likely that guideline-concordant care will lead to better controlled hypertension, which will reduce future hypertensionrelated complications. Dynamic state transmission models can estimate the long-term health and cost consequences of interventions, which seek to better control 
Table 4 Cost of hypertension in South African population with no private insurance

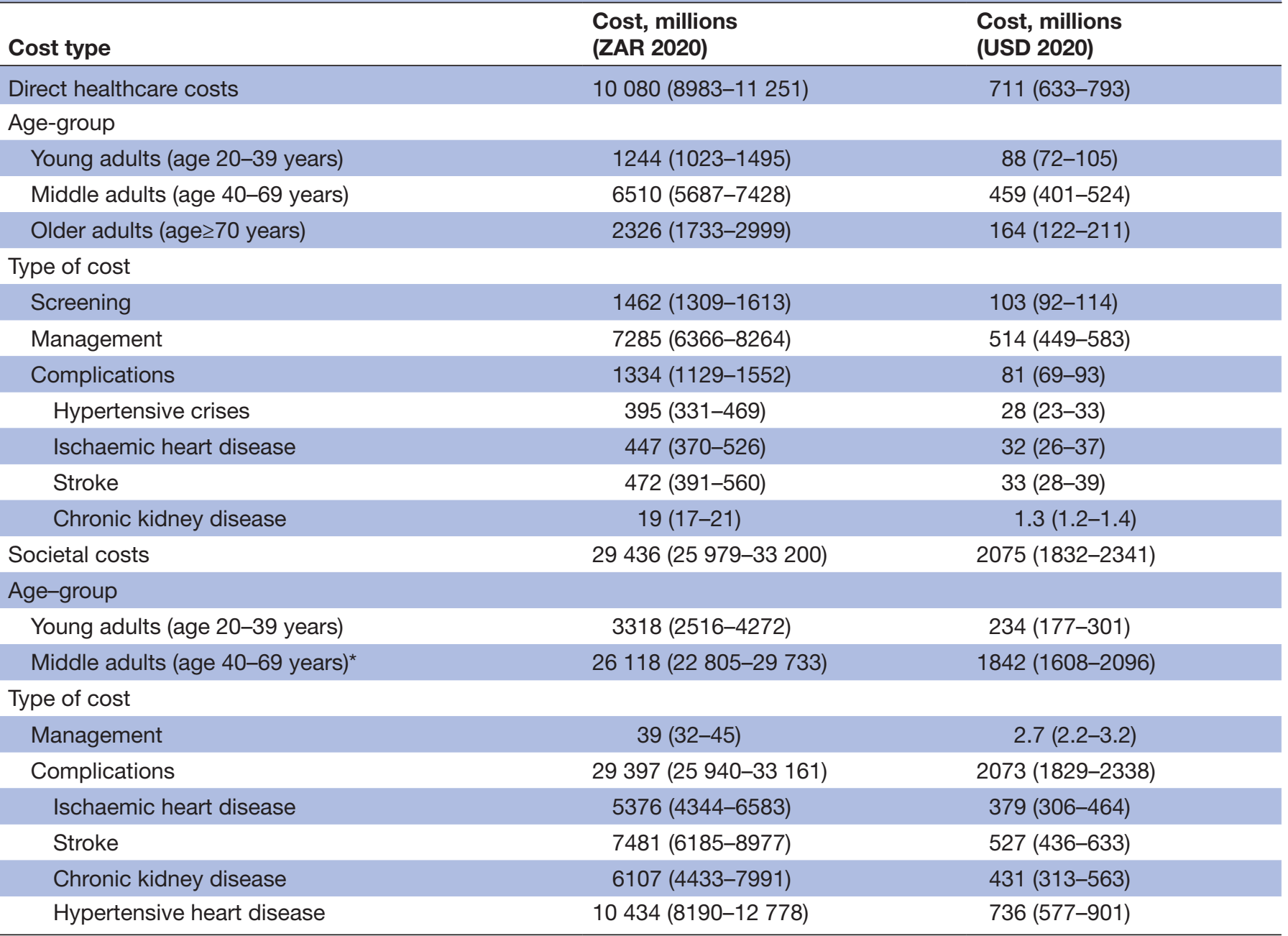

*Societal costs incurred until age 65.

hypertension. Previous studies have shown that scaling up current hypertension treatment guidelines would be costeffective for the healthcare sector. ${ }^{39}$ Programmes which train community health workers about hypertension to

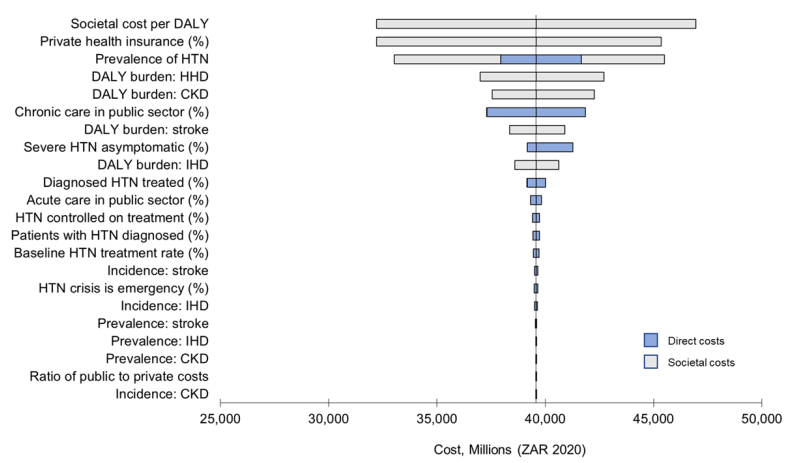

Figure 1 Tornado diagram showing results of sensitivity analyses. Figure indicates changes in direct healthcare and societal cost estimates associated with changing key model input parameters. CKD, chronic kidney disease; DALY, disability-adjusted life year; HHD, hypertensive heart disease; HTN, hypertension; IHD, ischaemic heart disease. improve medication adherence are also cost-effective. ${ }^{57}$ Such interventions are urgently required to save healthcare costs and ultimately improve population health. Further research should establish additional cost-effective strategies to upscale and improve hypertension care.

Hypertension tends to cluster with a number of other prominent risk factors for Noncommincable diseases (NCDs; eg, obesity, diabetes and high cholesterol). ${ }^{58} 59$ Healthcare decision-makers may take advantage of this clustering effect to efficiently target legislative or regulatory levers to reduce behaviours, which lead to high BP and other NCDs. Some such legislative actions have already taken place in South Africa (eg, mandatory salt regulations, a tax on sugary beverages). ${ }^{6061}$ Further costeffectiveness studies could consider the advent of food labels to promote healthier diets, banning the marketing unhealthy foods and beverages, provision of healthy foodstuffs to vulnerable populations and other interventions already in place globally. ${ }^{62}$

\section{Limitations}

As with many health economic evaluations conducted in low-income and middle-income countries, data availability 
was a limitation for this study. We synthesised data on the epidemiology of hypertension and costs of health services from multiple sources. Uncertainty from these sources will necessarily have propagated into our estimates. We explored this uncertainty with deterministic and probabilistic sensitivity analyses.

There is no system for the routine collection of national or subnational data in the South African public healthcare system. A 2015 governmental White Paper on NHI stated that a diagnosis-related grouping system will be developed for healthcare reimbursement along with an integrated national health information repository and data system. ${ }^{10}$ This system could inform future costing and cost-effectiveness studies. For example, our study would have benefited from information on clinical compliance to APC guidelines for hypertension management. Despite data limitations, a key strength of our analysis was that model inputs regarding the prevalence of hypertension, healthcare utilisation and the price of healthcare resources were all derived from South African data.

We used the GBDS 2019 to estimate hypertensionrelated complication rates. The GBDS is a wide-ranging study, which estimates disease incidence, prevalence and severity in 204 countries and territories. It accomplishes this by synthesising local epidemiologic data using complex statistical models. ${ }^{63}$ This multicountry approach to modelling in the GBDS survey may lead researchers to overlook important local insights. For example, Pillay-van Wyk et al reformulated South African mortality data to correct for misclassified HIV/AIDS mortality. ${ }^{64}$ They found that these adjustments led to significant variation between local and GBDS estimates of mortality and morbidity for several conditions including HHD and stroke.

When estimating societal costs, we assumed that GDP accounts for the total value of all goods and services made within a country. GDP may underestimate activity in the 'informal' labour market and informal work (eg, housekeeping, caretaking). ${ }^{65}$ Around 3.0 million South Africans work in the informal sector. ${ }^{13}$ Sensitivity analysis found that the way we valued DALYs greatly affected overall estimates of the societal cost of hypertension.

Finally, this costing analysis commenced during the COVID-19 pandemic. Many healthcare resources have been redirected towards the prevention and treatment of COVID-19 in South Africa. Much is still to be learnt about the relationship between COVID-19 and hypertension. Some studies suggest that hypertension is predictive of severe illness. ${ }^{66-68}$ Moreover, disruption in access to BP screening and management may have led to an increase in uncontrolled hypertension and its complications.

\section{CONCLUSION}

Hypertension is highly prevalent in South Africa. A large proportion of public healthcare budgets are spent screening, treating and controlling hypertension. An even greater economic burden is caused by reduced productivity attributable to the condition. Research is required to establish priority cost-effective strategies for lowering rates of hypertension and preventing complications.

Acknowledgements We would like to thank the editors and two reviewers for BMJ Open whose comments and suggestions helped to greatly improve and clarify this manuscript.

Contributors CKL developed the costing model, conducted the data analysis, interpreted results and wrote the first draft of the manuscript. As guarantor, CKL accepts full responsibility for the finished work, the conduct of the study, had access to the data and controlled the decision to publish. AE and KH developed the idea for the study, secured the funding and contributed to results interpretation, data analysis, and manuscript revisions. BR contributed to results interpretation, data analysis and manuscript revisions. All authors approved the final version of the manuscript.

Funding Financial support comes from Bloomberg Philanthropies through the University of North Carolina, with additional support from the South African Medical Research Council (grant code 23108).

Competing interests None declared.

Patient consent for publication Not applicable.

Ethics approval This study does not involve human participants; in accordance with University of the Witwatersrand guidelines on research ethics, this study did not require institutional review board approval as it was a secondary analysis of publicly available and de-identified data.

Provenance and peer review Not commissioned; externally peer reviewed.

Data availability statement Data are available in a public, open access repository. We used publicly available data to conduct our analysis. Access to the Microsoft Excel-based hypertension costing model is available by contacting ciaran.kohlilynch@northwestern.edu.

Supplemental material This content has been supplied by the author(s). It has not been vetted by BMJ Publishing Group Limited (BMJ) and may not have been peer-reviewed. Any opinions or recommendations discussed are solely those of the author(s) and are not endorsed by BMJ. BMJ disclaims all liability and responsibility arising from any reliance placed on the content. Where the content includes any translated material, BMJ does not warrant the accuracy and reliability of the translations (including but not limited to local regulations, clinical guidelines, terminology, drug names and drug dosages), and is not responsible for any error and/or omissions arising from translation and adaptation or otherwise.

Open access This is an open access article distributed in accordance with the Creative Commons Attribution Non Commercial (CC BY-NC 4.0) license, which permits others to distribute, remix, adapt, build upon this work non-commercially, and license their derivative works on different terms, provided the original work is properly cited, appropriate credit is given, any changes made indicated, and the use is non-commercial. See: http://creativecommons.org/licenses/by-nc/4.0/.

ORCID iD

Ciaran N Kohli-Lynch http://orcid.org/0000-0001-5516-1862

\section{REFERENCES}

1 Mills KT, Stefanescu A, He J. The global epidemiology of hypertension. Nat Rev Nephrol 2020;16:223-37.

2 Ware LJ, Chidumwa G, Charlton K, et al. Predictors of hypertension awareness, treatment and control in South Africa: results from the WHO-SAGE population survey (wave 2). J Hum Hypertens 2019;33:157-66.

3 Berry KM, Parker W-A, Mchiza ZJ, et al. Quantifying unmet need for hypertension care in South Africa through a care cascade: evidence from the SANHANES, 2011-2012. BMJ Glob Health 2017;2:e000348.

4 Thomas R, Burger R, Hauck K. Richer, wiser and in better health? the socioeconomic gradient in hypertension prevalence, unawareness and control in South Africa. Soc Sci Med 2018;217:18-30.

5 World Bank. World bank country and lending groups, 2019. Available: https://datahelpdesk.worldbank.org/knowledgebase/articles/906519world-bank-country-and-lending-groups [Accessed 02 Jan 2019].

6 Kamerman P. Underdiagnosis of hypertension and diabetes mellitus in South Africa. S Afr Med J 2022;112:13519. 
7 Hasumi T, Jacobsen KH. Hypertension in South African adults: results of a nationwide survey. J Hypertens 2012;30:2098-104.

8 Statistics South Africa, Government of the Republic of South Africa. General household survey 2018. Pretoria: Statistics South Africa, Government of the Republic of South Africa, 2018.

9 OECD. Health expenditure and financing data. South Africa. Paris, 2017.

10 Government of South Africa. White paper on national health insurance: towards universal health coverage. Pretoria: Government of South Africa, 2015.

11 Gheorghe A, Griffiths U, Murphy A, et al. The economic burden of cardiovascular disease and hypertension in low- and middleincome countries: a systematic review. BMC Public Health 2018;18:975

12 Norman R, Gaziano T, Laubscher R, et al. Estimating the burden of disease attributable to high blood pressure in South Africa in 2000. S Afr Med J 2007:97:692-8.

13 Statistics South Africa, Government of the Republic of South Africa. Quarterly labour force survey. quarter 2: 2020. Pretoria: Statistics South Africa, Government of the Republic of South Africa, 2020.

14 DataFirst 2013

15 Statistics South Africa, Government of the Republic of South Africa. Mid-Year population estimates 2020. Pretoria: Statistics South Africa, Government of the Republic of South Africa, 2020.

16 Statistics South Africa, Government of the Republic of South Africa. South Africa demographic and health survey 2016. Pretoria: Statistics South Africa, Government of the Republic of South Africa, 2016.

17 Southern Africa Labour and Development Research Unit, University of Cape Town. National income dynamics survey 2017. Cape Town: Southern Africa Labour and Development Research Unit, University of Cape Town, 2018

18 Cois A, Ehrlich R. Antihypertensive treatment and blood pressure trends among South African adults: a repeated cross-sectional analysis of a population panel survey. PLoS One 2018;13:e0200606.

19 Branson N, Wittenberg M. Longitudinal and cross-sectional weights in the NIDS data 1-5. Cape Town: Southern Africa Labour and Development Research Unit, University of Cape Town, 2019.

20 National Department of Health, Government of the Republic of South Africa. Adult primary care 2018/19. Pretoria: National Department of Health, Government of the Republic of South Africa, 2019.

21 Korn EL, Graubard BI. Variance estimation for SUPERPOPULATION parameters. Stat Sin 1998;8:1131-51.

22 National Department of Health, Government of South Africa. Uniform patient fee schedule 2020. Pretoria: National Department of Health, Government of South Africa, 2020.

23 National Department of Health, Government of South Africa. User Manual - Uniform Patient Fee Schedule 2009. Pretoria: National Department of Health, Government of South Africa, 2015.

24 , Seedat YK, Rayner BL, et al, Hypertension guideline working group. South African hypertension practice guideline 2014. Cardiovasc J Afr 2014:25:288-94.

25 National Treasury, Government of South Africa. The supply and delivery of solid dosage forms to the state 1 may 2019 to 30 April 2021. Pretoria, 2020

26 Marik PE, Varon J. Hypertensive crises: challenges and management. Chest 2007:131:1949-62.

27 Patel KK, Young L, Howell EH, et al. Characteristics and outcomes of patients presenting with hypertensive urgency in the office setting. JAMA Intern Med 2016;176:981-8.

28 Nakalema I, Kaddumukasa M, Nakibuuka J, et al. Prevalence, patterns and factors associated with hypertensive crises in Mulago hospital emergency department; a cross-sectional study. Afr Health Sci 2019;19:1757-67.

29 Shao PJ, Sawe HR, Murray BL, et al. Profile of patients with hypertensive urgency and emergency presenting to an urban emergency department of a tertiary referral hospital in Tanzania. BMC Cardiovasc Disord 2018;18.

30 Wierzejska E, Giernaś B, Lipiak A, et al. A global perspective on the costs of hypertension: a systematic review. Arch Med Sci 2020;16:1078-91.

31 Elliott WJ. The economic impact of hypertension. J Clin Hypertens 2003;5:3-13.

32 James SL, Abate D, Abate KH, et al. Global, regional, and national incidence, prevalence, and years lived with disability for 354 diseases and injuries for 195 countries and territories, 1990-2017: a systematic analysis for the global burden of disease study 2017 . The Lancet 2018;392:1789-858.

33 Global Health Data Exchange Portal. Global burden of disease study 2019Institute for health metrics and evaluation (IHME. Seattle, WA: Global Health Data Exchange Portal, 2019.
34 Murray CJ, Acharya AK. Understanding DALYs (disability-adjusted life years). $J$ Health Econ 1997;16:703-30.

35 Ahern RM, Lozano R, Naghavi M, et al. Improving the public health utility of global cardiovascular mortality data: the rise of ischemic heart disease. Popul Health Metr 2011;9:8.

36 Mansournia MA, Altman DG. Population attributable fraction. BMJ 2018;360:k757.

37 WHO CVD Risk Chart Working Group. World Health organization cardiovascular disease risk charts: revised models to estimate risk in 21 global regions. Lancet Glob Health 2019;7:e1332-45.

38 Singh GM, Danaei G, Farzadfar F, et al. The age-specific quantitative effects of metabolic risk factors on cardiovascular diseases and diabetes: a pooled analysis. PLoS One 2013;8:e65174.

39 Basu S, Wagner RG, Sewpaul R, et al. Implications of scaling up cardiovascular disease treatment in South Africa: a microsimulation and cost-effectiveness analysis. Lancet Glob Health 2019;7:e270-80.

40 Government Employees Medical Scheme. Tariff for consultative services by contracted medical practitioners. Cape Town: Government Employees Medical Scheme, 2019.

41 Gerntholtz T, Paget G, Hsu P, et al. Management of patients with chronic kidney disease. S Afr Med J 2015;105:237.

42 Davids MR, Jardine T, Marais N, et al. South African renal registry annual report 2017. African Journal of Nephrology 2019;22:60-71.

43 Erzse A, Stacey N, Chola L, et al. The direct medical cost of type 2 diabetes mellitus in South Africa: a cost of illness study. Glob Health Action 2019;12:1636611.

44 Oostvogels AJJM, De Wit GA, Jahn B, et al. Use of DALYs in economic analyses on interventions for infectious diseases: a systematic review. Epidemiol Infect 2015;143:1791-802.

45 Hird TR, Zomer E, Owen AJ, et al. Productivity burden of hypertension in Australia. Hypertension 2019;73:777-84.

46 The World Bank. GDP per Capita (Current USD) - South Africa. Washington D.C.: The World Bank, 2020.

47 Bloomberg. USD to ZAR exchange rate n.d. Available: https://www. bloomberg.com/quote/USDZAR:CUR [Accessed September 14, 2020].

48 Leshoro TLA. Estimating the inflation threshold for South Africa. Studies in Economics and Econometrics 2012;36:53-66.

49 Statistics South Africa, Government of the Republic of South Africa. Consumer price index. Pretoria: Statistics South Africa, Government of the Republic of South Africa, 2020.

50 National Treasury. Estimates of national expenditure 2020. Pretoria: Government of South Africa, 2020.

51 The World Bank. GNI per Capita, Atlas Method (Current US\$). World Bank Open Data, 2020. Available: https://data.worldbank.org/ indicator/NY.GNP.PCAP.CD [Accessed 02 Sep 2020].

52 Boachie MK, Rossouw L, Ross $\mathrm{H}$. The economic cost of smoking in South Africa, 2016. Nicotine Tob Res 2021;23:286-93.

53 Matzopoulos RG, Truen S, Bowman B, et al. The cost of harmful alcohol use in South Africa. S Afr Med J 2014;104:127-32.

54 Wandai ME, Norris SA, Aagaard-Hansen J, et al. Geographical influence on the distribution of the prevalence of hypertension in South Africa: a multilevel analysis. Cardiovasc J Afr 2020;31:47-54.

55 Basu S, Millett C, Sanjay B. Social epidemiology of hypertension in middle-income countries: determinants of prevalence, diagnosis, treatment, and control in the who SAGE study. Hypertension 2013;62:18-26.

56 Sharma JR, Mabhida SE, Myers B, et al. Prevalence of hypertension and its associated risk factors in a rural black population of Mthatha town, South Africa. Int J Environ Res Public Health 2021;18:1215.

57 Gaziano TA, Bertram M, Tollman SM, et al. Hypertension education and adherence in South Africa: a cost-effectiveness analysis of community health workers. BMC Public Health 2014;14:240.

58 Gómez-Olivé FX, Ali SA, Made F, et al. Regional and sex differences in the prevalence and awareness of hypertension: an H3Africa AWI-Gen study across 6 sites in sub-Saharan Africa. Glob Heart 2017;12:81-90.

59 Gillis EE, Sullivan JC, Sullivan Jennifer C. Sex differences in hypertension. Hypertension 2016;68:1322-7.

60 Kaldor JC, Thow AM, Schönfeldt $\mathrm{H}$. Using regulation to limit salt intake and prevent non-communicable diseases: lessons from South Africa's experience. Public Health Nutr 2019;22:1316-25.

61 Stacey N, Mudara C, Ng SW, et al. Sugar-Based beverage taxes and beverage prices: evidence from South Africa's health promotion levy. Soc Sci Med 2019;238:112465.

62 Hyseni L, Atkinson M, Bromley $\mathrm{H}$, et al. The effects of policy actions to improve population dietary patterns and prevent diet-related non-communicable diseases: Scoping review. Eur J Clin Nutr 2017;71:694-711.

63 Vos T, Lim SS, Abbafati C, et al. Global burden of 369 diseases and injuries in 204 countries and territories, 1990-2019: a systematic 
analysis for the global burden of disease study 2019. Lancet 2020;396:1204-22.

64 Pillay-van Wyk V, Msemburi W, Laubscher R, et al. Mortality trends and differentials in South Africa from 1997 to 2012: second National burden of disease study. Lancet Glob Health 2016;4:e642-53.

65 England RW. Measurement of social well-being: alternatives to gross domestic product. Ecological Economics 1998;25:89-103.

66 Schiffrin EL, Flack JM, Ito S, et al. Hypertension and COVID-19. Am $J$ Hypertens 2020;33:373-4.
67 Tadic M, Cuspidi C, Mancia G, et al. COVID-19, hypertension and cardiovascular diseases: should we change the therapy? Pharmacol Res 2020;158:104906.

68 Clark CE, McDonagh STJ, McManus RJ, et al. COVID-19 and hypertension: risks and management. A scientific statement on behalf of the British and Irish hypertension Society. J Hum Hypertens 2021;35:304-7.

69 National Health Laboratory Service. NHLS price list 2013. Johannesburg: National Health Laboratory Service, 2013. 